\title{
Review
}

\section{The right to sex}

Amia Srinivasan

(Ed.), Bloomsbury, London, 2021, xvi+276 pp.,

ISBN: HB978-1-5266-1253-3

Contemporary Political Theory (2022). https://doi.org/10.1057/s41296-022-00554-9

What would it take to end the political, social, sexual, economic, psychological, and physical subordination of women? And: what would it take for sex to be free? These are fundamental, thorny questions. They are, according to Amia Srinivasan, the questions that lead feminism not so much as a theoretical endeavor, but first and foremost as a political movement. Although The Right to Sex announces that it is going to address these questions in its preface, Srinivasan admits that she does not know how to answer them - 'let's try and see' (p. xiii). The hesitation is not merely rhetorical. It also means that, as societies and communities, we still have to think, to discuss, but, mostly, to struggle and to conduct 'experiments of living' (p. 102) in order to realize desirable and plausible answers.

Srinivasan's questions are quite different from those currently animating academic theoretical discourses in the field. For example, they do not look for a conceptualization of what oppression is. They do not delve into the shortcomings of intersectionalist approaches either. The first question is a practical one: it looks for strategies to effectively achieve emancipatory social change. The second question seems to additionally require some form of utopian thinking. If 'freedom is a constant struggle' (Angela Davis), some conditions, figures, images and models of what we are struggling for are needed.

Srinivasan's debut has been promptly celebrated as an essential reading for our post-\#MeToo moment. The six essays put together in The Right to Sex span a vast range of controversial issues (various forms of sexual harassment and violence, pornography, the phenomenon of so-called incels, sex education), deal with them by relying upon a rich mix of resources (from personal anecdotes to philosophical arguments, from journalistic reports to historical overviews), and provide refined analyses and diagnoses. In trying to delineate responses to her two initial questions, however, Srinivasan loses courage, gets back into line. She does not dare to experiment. Let's consider the two orders of issues separately.

(c) 2022 The Author(s), under exclusive licence to Springer Nature Limited. 1470-8914 Contemporary Political 


\section{Liberation from oppression}

Srinivasan's central thesis consists in a problematization of consent. No means no, but yes is not always yes. Sexual and intimate practices may be deeply problematic and damaging even if they are based on the explicit free and autonomous agreement of all participants. We can say yes to certain things because we enjoy and strive for them; our preferences and desires, however, are often built on sexist, heteronormative, racist, ableist deeply engrained structures and habits.

Srinivasan avoids the trap of a critique of false consciousness, as well as the unpleasantness of moralizations. She does not say that desires and preferences entangled with problematic structures and habits are not authentic or wrong. Rather, she encourages us to ask ourselves uncomfortable questions - what are the underlying conditions, motives, origins of what we like and want? The aim is not to discipline desire, but to push against the ways in which we have been disciplined, since birth, to regard only certain types of bodies as worthy, beautiful, 'fuckable' (p. 103).

The problematization of a consent-based feminist critical theory is also the basis, as I read it, of Srinivasan's second major point, which corresponds to her conviction that the law and the judicial system are not the right medium for solving the most controversial problems faced by feminism today - especially from the perspectives of women of color, or of queer and non-cis persons. Note that Srinivasan's theorization of liberation from oppression is essentially negative: consent is not enough, the law is not enough (sometimes, both are part of the problem). But the question of emancipatory transformation would require at least a few positive indications as well.

Is normative theory right for the job though, as Sally Haslanger (2021) suggests in her review? Many critical theorists have shown that normative prescriptions about what has to be done, if not already at play in current objective social dynamics and movements, are merely naïve and ultimately empty operations. A discourse on emancipation also needs descriptive, ontological conceptualizations, e.g., of how moral, political, and social progress might occur. Many proposals have been elaborated to explain emancipatory social movements (e.g., those based on notions of recognition, habit, affects). Alas, Srinivasan does not mention any of them.

However, there is a passage in The Right to Sex, dedicated to the practice and ethics of teaching, that exceeds negativism: this happens when Srinivasan gives her own personal example as a teacher. The move deserves philosophical attention, as it goes beyond both normative theorizing and critical social ontology. Her point here is that teachers who sleep with their students fail, as teachers, for they do not give them what they really want and need, which is an education, and not sexual thrill or romance. And the real reason why teachers are tempted to initiate, or give

(C) 2022 The Author(s), under exclusive licence to Springer Nature Limited. 1470-8914 Contemporary

Political Theory 
in to sexual or romantic escapades, is the desire for retrieving an intensity and adventurousness of life they feel they have lost. (There is an argumentative last step that Srinivasan fails to take: for her reasoning to hold, she should have shown why the education that still may happen between teachers and students who become lovers is a damaged and damaging one.) As in many other passages of the book, Srinivasan convincingly explains power on the basis of desire, and not vice versa. In this case, this is not just a theoretical point. As such, it shakes the reader: it might set in motion processes of (self-)questioning, have a therapeutical effect, shed a new light on past traumatic experiences.

We surely need more positive examples of this sort. But I wonder whether this radiant positivity alone would not risk becoming overwhelming, thus discouraging, widening the gap between ideal role models and the majority of us, imperfect, confused, 'bad' feminists (Roxane Gay). Feminist movements, it seems to me, unfold through personal examples of another sort as well. There are indeed thinkers and activists - I am thinking of Virginie Despentes or Rebecca Solnit for example who have most effectively taught us through what can be called 'negative exemplarity': not by showing how to be good, but by exposing the mistakes, failed experiments, self-doubts, bewilderments they have gone through to become who they are.

\section{After liberation, freedom}

How to imagine and desire free-desire? Can we figure out sexual practices that are at the same time delightful, enjoyable, and free from oppression? This is hard. Srinivasan ends up dashing any enthusiasm when discussing the legacy of the sexual revolution, which has left almost everything 'unchanged' (p. 121). 'We have never yet been free' (p. 122). Never?! The problem with this pessimist claim is twofold.

The first one is highlighted by Maggie Nelson in her Ballad of Sexual Optimism, an essay that shares many of Srinivasan's concerns, but stands out in the end as much messier, queerer, and hence more experimental: freedom is a chiaroscuro and is itself a process of change. Phases of liberation give rise to new forms of oppression, liberties are gained and lost, what appears as freedom at a certain moment in time, and from the perspective of a certain social group, does sometimes shade or even hinder the freedom of others. This is particularly true for the realm of sex (Nelson, 2021, p. 78), full of 'gray areas' (Nelson, 2021, p. 80). Trying to conceptually go through them does not mean we have to give up critical work or justify the status quo. On the contrary, emancipatory change works better if we give up on the pernicious dualism freedom vs. unfreedom. When liberated from the obsession of perfect, full freedom, we might become able to spell out some of the things that would indeed make us free. 
In principle, Srinivasan shares this view (p. xv). But she tends to dispel the ambiguity by predominantly concentrating on the negative sides of sex and desire. For example, the major part of her essay on pornography consists of criticisms of the mainstream porn industry, picking up arguments presented in the 70s and 80s. In the end, alternatives are sketched, but only very briefly and weakly. This is a pity: the chapter misses an opportunity to outline a model of 'sex education' by getting into what I believe are the most interesting debates on the topic. There are many practices that claim to be ethical, e.g., feminist, lesbian, queer pornography. And as such, they open up many important questions, for instance: what does it take for pornography in order for it to be not just ethical, but critical and emancipatory? Can heteronormative problematic forms of desire be really changed through nonmainstream pornography? What about the relationship between pornography and art?

The second problem is Srinivasan's only negative, and thus limited view of freedom. As Judith Butler (2021) points out, a shortcoming of The Right to Sex is that it does not consider 'the right to have sex claimed by those,' namely by LGBTQI people, 'who have been illegitimately denied that right.' This is due to the fact that Srinivasan sees freedom as mostly a masculine, white supremacist, market-driven endeavor. But freedom can and should be more than that. To understand the ways in which we are (becoming) free by participating in the (ambivalent, conflictual) processes of freedom, we need an enlarged conception: to think of freedom in collective terms, in terms of the possible alternatives that we can and must build up together.

\section{References}

Butler, J. 2021. Whose freedom? The New Statesman.

Haslanger, S. 2021. Feminism and the Question of Theory. The Raven.

Nelson, M. (2021) On Freedom. Four Songs of Care and Constraint. Penguin.

Publisher's Note Springer Nature remains neutral with regard to jurisdictional claims in published maps and institutional affiliations.

Federica Gregoratto

University of St. Gallen, 9000 St. Gallen, Switzerland federica.gregoratto@unisg.ch 